\title{
Zinc and Copper Nutritional Studies in Very Low Birth Weight Infants: Comparison of Stable Isotopic Extrinsic Tag and Chemical Balance Methods $^{1}$
}

\author{
RICHARD A. EHRENKRANZ, PATRICIA A. GETTNER, CATHERINE M. NELLI, \\ ELAINE A. SHERWONIT, JOANNE E. WILLIAMS, BILL T. G. TING, AND \\ MORTEZA JANGHORBANI
}

\begin{abstract}
Department of Pediatrics and Obstetrics and Gynecology and the Children's Clinical Research Center, Yale University School of Medicine, New Haven, Connecticut 06510 [R.A.E., P.A.G., C.M.N., E.A.S., J.E.W.]; and Clinical Nutrition Research Unit, Department of Medicine, University of Chicago, Chicago, Illinois 60637
\end{abstract} [B.T.G.T., M.J.]

\begin{abstract}
Measurements of dietary zinc and copper absorption obtained after administration of a single dose of the extrinsic stable isotopic tags ${ }^{70} \mathrm{Zn}$ and ${ }^{65} \mathrm{Cu}$ were compared to measurements made with standard chemical balance methods in $\mathbf{4 1}$ appropriate for gestational age premature infants [body wt $1267 \pm 258 \mathrm{~g}$, gestational age $29.8 \pm 1.9$ wk (mean $\pm \mathrm{SD}$ ), 4 to 83 postnatal $d$ of age]. Fifty studies were performed; 33 with premature formula, five with term formula, seven with preterm human milk (PTHM), and five with fortified-PTHM. The percentages of net zinc and ${ }^{70} \mathrm{Zn}$ absorption were found to be significantly greater from PTHM $(66.4 \pm 15.2,68.6 \pm 9.8)$ than from premature formula $(14.0 \pm 29.9,31.6 \pm 22.4)$, and term formula $(23.6 \pm 18.5,17.6 \pm 5.6)$. The percentages of net copper and ${ }^{65} \mathrm{Cu}$ absorption were also found to be significantly greater from PTHM (61.5 $\pm 14.0,69.8 \pm$ 14.0) than from premature formula $(16.6 \pm 20.6,39.6 \pm$ 21.6) and term formula $(20.6 \pm 24.1,26.5 \pm 6.9)$. The percentages of net zinc and ${ }^{70} \mathrm{Zn}$ absorption $(35.9 \pm 29.1$, 48.4 \pm 9.6) and net copper and ${ }^{65} \mathrm{Cu}$ absorption $(38.7 \pm$ 10.2 and $57.4 \pm 13.1$ ) from fortified PTHM were similar to values from PTHM. Absorption of zinc and copper determined with extrinsic stable isotopic tag and standard nutrient balance methods were significantly correlated. Estimates of endogenous fecal losses of zinc and copper were substantial with each diet, but lower with PTHM. Stepwise, multiple linear regression analysis accounted for, at most, $58 \%$ of the variability in the measures of zinc and copper availability. We conclude that extrinsic ${ }^{70} \mathrm{Zn}$ and ${ }^{65} \mathrm{Cu}$ tags can be used to study absorption of dietary zinc and copper by very low birth wt infants. (Pediatr Res 26:298-307, 1989)
\end{abstract}

\section{Abbreviations}

VLBW, very low birth wt

PTHM, preterm human milk

F-PTHM, fortified PTHM

Received January 17, 1989; accepted May 22, 1989.

Correspondence and reprint requests Dr. Richard A. Ehrenkranz, Department of Pediatrics, Yale University School of Medicine, 333 Cedar Street, New Haven, CT 06510. Supported by grant from the National Institute of Child Health and Human Development, Grant HD 17498, the Children's Clinical Research Center, RR-00125 NIH, and the Mead Johnson Nutritional Group.

${ }^{1}$ Presented in part at the Annual Meeting of the Society for Pediatric Research in May 1986 and in May 1989.
$P F$, premature formula

MCT, medium-chain triglycerides

TF, term formula

Current recommendations regarding the nutritional needs of growing VLBW infants have been based upon estimates of the daily intrauterine increment of the body content of each nutrient and upon estimates of gastrointestinal nutrient absorption and maintenance nutrient requirements $(1,2)$. However, the standard nutrient balance methodology used to measure gastrointestinal absorption often produces variable results (3). Nonrandom collection errors and irregularities in fecal excretion tend to overestimate both absorption and retention. Furthermore, because these studies are primarily based on determinations of dietary intake and fecal excretion, and do not specifically measure endogenous fecal nutrient loss, they only provide a measure of net nutrient balance across the intestinal tract, and tend to underestimate absorption.

We $(4,5)$ and others $(6-9)$ have recently demonstrated that the extrinsic tag approach with stable isotope methods can be successfully used to study absorption of dietary minerals by growing infants. This methodology is based upon the use of naturally occurring, nonradioactive isotopes as tracers $(10,11)$. It assumes that the extrinsic tag is handled in the gastrointestinal tract similarly to intrinsic dietary nutrient.

This investigation was designed to compare measurements of dietary zinc and copper absorption obtained with extrinsic stable isotopic tags to measurements made with standard chemical balance methods. By performing both of these measurements, we hoped to estimate true and net absorption and endogenous fecal losses of these minerals. In addition, we hoped to assess the influence of type of feeding (PTHM or F-PTHM) and postnatal and postconceptional age on dietary zinc and copper absorption.

\section{MATERIALS AND METHODS}

Subjects. Forty-one appropriate for gestational age infants with birth wt less than or equal to $1660 \mathrm{~g}(1267 \pm 258 \mathrm{~g}$, mean \pm SD) and gestational ages less than or equal to $34 \mathrm{wk}(29.8 \pm 1.9 \mathrm{wk})$ who were cared for in the Newborn Special Care Unit, YaleNew Haven Hospital because of prematurity were enrolled in this investigation after enteral (nasogastric) feedings had been 
established. Each infant had tolerated enteral nutrition of about $100 \mathrm{kcal} / \mathrm{kg} / \mathrm{d}$ by $7 \mathrm{~d}$ of age. Each infant was managed according to presently accepted standards of care for premature infants. Permission to include each infant in the study was obtained by informed consent of the parents. This protocol was approved by the Human Investigation Committee, Yale University School of Medicine.

Feeding regimen. Enteral feedings were initiated at the discretion of the medical staff caring for the infants. Caloric intake was optimized as quickly as the infant would tolerate and was adjusted to maintain a gross intake of 100 to $120 \mathrm{kcal} / \mathrm{kg} / \mathrm{day}$ in accordance with nursery feeding policies. Dietary assignment was dictated by parental preference; 31 of the 41 study infants received formula and the remaining 10 study infants received milk expressed by their own mothers.

Formula-fed infants were initially given a proprietary premature formula (Enfamil Premature Formula, Mead Johnson Nutritionals, Evansville, IN) until reaching a body wt of about 1750 g. Then they were switched to a proprietary term formula (Enfamil with Iron, Mead Johnson Nutritionals, or Similac with Iron, Ross Laboratories, Columbus, OH). According to product information, the PF contained $40 \%$ of its fats as MCT, $810 \mu \mathrm{g}$ zinc/dL, and $70 \mu \mathrm{g}$ copper/dL; the TF contained predominantly long-chain triglycerides with $520 \mu \mathrm{g}$ zinc/dL and $63 \mu \mathrm{g}$ copper/ $\mathrm{dL}$ or $510 \mu \mathrm{g}$ zinc/dL and $61 \mu \mathrm{g}$ copper/dL, respectively.

Human milk was expressed about four to six times per day, primarily with an electric breast pump (Egnell Electric Breast Pump, Egnell Inc, Gary, IL or Medela Electric Breast Pump, Medela Inc, Crystal Lake, IL). It was stored without pooling or pasteurization in plastic containers in a Human Milk Bank maintained within the Newborn Special Care Unit and was fed to the infants in the order in which it was expressed. If the milk could be fed to the infant within 48 hours of collection, it was refrigerated at $4^{\circ} \mathrm{C}$. Otherwise, it was frozen $\left(-4^{\circ} \mathrm{C}\right)$ and then gently thawed and warmed before each feeding. Infants receiving PTHM were initially fed full strength human milk for 5 to $7 \mathrm{~d}$ and were then given human milk fortified with a powdered protein-mineral supplement that was designed to increase milk zinc and copper content by 800 and $40 \mu \mathrm{g} / \mathrm{dL}$, respectively (Human Milk Fortifier, Mead Johnson Nutritionals). Preparation of the F-PTHM has been previously described (12). When these infants reached a body wt of about $1750 \mathrm{~g}$, the fortifier was discontinued and they received only human milk.

All of the infants were tube fed by intermittent gavage; a measured feeding volume being pushed from a plastic syringe through an indwelling nasogastric tube over about a 10-min period. The formula was drawn up into the syringe after vigorous shaking of a ready-to-feed bottle. Human milk and F-PTHM were also vigorously shaken before being drawn up into the syringe. The nasogastric tube was changed daily. Recommended vitamin intakes were achieved with vitamin supplements [1.0 $\mathrm{mL}$ Poly-vi-Sol/day (Mead Johnson Nutritionals) or vitaminenriched formulas. Isolette temperature was maintained in the neutral thermal zone.

Nutritional balance study design. At the time of each balance period, each infant had to be stable, tolerating feedings, and gaining wt steadily. In addition, each infant had to meet the following requirements: 1 ) no longer need ventilatory assistance or supplemental oxygen; 2) never had confirmed necrotizing enterocolitis or other significant disorder that resulted in an interruption in enteral feedings for longer than $48 \mathrm{~h} ; 3$ ) not have a congenital malformation of the gastrointestinal tract; and 4) not require treatment with medications that might affect mineral absorption and/or excretion.

Dietary intake of fat, nitrogen, zinc, and copper was determined for each balance period. Aliquots of each lot of formula consumed by the formula-fed infants were analyzed. For each infant receiving PTHM and F-PTHM during the balance period, equal aliquots of PTHM were taken at each feeding before addition of the powdered fortifier, and pooled for analyses. The composition of F-PTHM was calculated as previously described (12). Residual formula, PTHM, or F-PTHM in the syringe used for feeding was minimal. Gastric residuals, determined before each tube feeding in accordance with standard nursing policy, were refed. In addition, losses from vomitus or regurgitation were minimal.

Each nutritional balance study included a stool and urine collection. Stool was collected as previously described (12) and represented $72 \mathrm{~h}$ of dietary intake. The stool collection was defined by the appearance of two doses of carmine red $(100 \mathrm{mg})$ given $72 \mathrm{~h}$ apart. If an infant took longer than $48 \mathrm{~h}$ to pass the first carmine red marked stool, activated charcoal (100 mg) was administered instead of the second carmine red dose to define the stool collection period. The time for passage of the carmine red (or charcoal) marked stool (i.e. transit time) was recorded twice during each balance study and was averaged for each infant. Stool passed during the collection period was pooled, weighed homogenized with deionized water, aliquotted for fat, nitrogen, and zinc and copper isotopic analyses, and then frozen at $-20^{\circ} \mathrm{C}$.

Urine was collected during the 72 -h period bracketed by the two doses of carmine red as previously described (12). Urine excreted during the collection period was pooled, the total volume was determined, it was aliquotted for nitrogen, creatinine, zinc, and copper analyses, and then frozen at $-20^{\circ} \mathrm{C}$.

The stable isotope dose containing the extrinsic tags ${ }^{70} \mathrm{Zn}$ and ${ }^{65} \mathrm{Cu}$ was equilibrated with a portion of the feeding for 2 to $3 \mathrm{~h}$ and then administered 6 to $9 \mathrm{~h}$ after the first carmine red stool marker. Inasmuch as our previous studies $(4,5)$ had demonstrated that a fecal collection period of about $50 \mathrm{~h}$ from administration of the stable isotope dose was sufficient for a complete collection of the unabsorbed extrinsic isotopic tag, this experimental design was chosen to insure that all of the unabsorbed stable isotope dose would be contained within the stool passed between the stool markers. In addition, the stable isotope dose was mixed with a portion of the feeding for several hours before administration so that it would be handled by the gastrointestinal tract similar to intrinsic dietary zinc and copper.

Preparation and administration of stable isotopes. Zinc oxide $(20.47 \mathrm{mg})$, with an 85.03 atoms percent enrichment of ${ }^{70} \mathrm{Zn}$, and copper oxide $(21.60 \mathrm{mg})$, with a 99.69 atoms percent enrichment of ${ }^{65} \mathrm{Cu}$ (Oak Ridge National Laboratory, Oak Ridge, TN), were dissolved separately in the smallest possible volume of reagent grade hydrochloric acid (37\%) and diluted to $50 \mathrm{~mL}$ in volumetric flasks with deionized water. These solutions were then combined and diluted with additional deionized water to a final volume of $350 \mathrm{~mL}(\mathrm{pH} \sim 3)$. This solution had an elemental zinc concentration of $47.1 \mu \mathrm{g} / \mathrm{mL}, \mathrm{a}^{70} \mathrm{Zn}$ concentration of 40.1 $\mu \mathrm{g} / \mathrm{mL}$, an elemental copper concentration of $49.2 \mu \mathrm{g} / \mathrm{mL}$ and a ${ }^{65} \mathrm{Cu}$ concentration of $49.1 \mu \mathrm{g} / \mathrm{mL}$. There are five stable isotopes of zinc; ${ }^{70} \mathrm{Zn}$ is the least abundant, accounting for 0.62 atoms percent of natural zinc. There are only two stable isotopic forms of copper; ${ }^{65} \mathrm{Cu}$ accounts for 30.9 atoms percent of natural copper.

The dose of ${ }^{70} \mathrm{Zn}$ and ${ }^{65} \mathrm{Cu}$ was chosen from an estimate of the daily dietary intake of each mineral, assuming an intake of 150 $\mathrm{mL} / \mathrm{kg} / \mathrm{d}$ and the label content of zinc and copper. The dose of ${ }^{70} \mathrm{Zn}$ provided approximately a 10 -fold enrichment of one day's dietary intake of ${ }^{70} \mathrm{Zn}$. The dose of ${ }^{65} \mathrm{Cu}$ approximated one day's dietary intake of copper, about a 3-fold enrichment of the day's ${ }^{65} \mathrm{Cu}$ intake. PF-fed and F-PTHM-fed infants received about $120.2 \mu \mathrm{g}{ }^{70} \mathrm{Zn} / \mathrm{kg}$ and $147.3 \mu \mathrm{g}{ }^{65} \mathrm{Cu} / \mathrm{kg}(3.0 \mathrm{~mL}$ isotope solution/ $\mathrm{kg}$, rounded to the nearest $0.5 \mathrm{~mL}$ ). TF-fed infants received about $80.2 \mu \mathrm{g}{ }^{70} \mathrm{Zn} / \mathrm{kg}$ and about $98.2 \mu \mathrm{g}{ }^{65} \mathrm{Cu} / \mathrm{kg}(2.0 \mathrm{~mL}$ isotope solution $/ \mathrm{kg}$, rounded to the nearest $0.5 \mathrm{~mL}$ ). PTHM-fed infants received about $40.1 \mu \mathrm{g}{ }^{70} \mathrm{Zn} / \mathrm{kg}$ and about $49.1 \mu \mathrm{g}{ }^{65} \mathrm{Cu} / \mathrm{kg}(1.0$ $\mathrm{mL}$ isotope solution $/ \mathrm{kg}$ rounded to the nearest $0.25 \mathrm{~mL}$ ). In reality during the study period, the stable isotope solution was found to increase average daily dietary zinc intake by about $7 \%$ and average daily dietary copper intake by about $35 \%$. Therefore, although the ${ }^{70} \mathrm{Zn}$ dose can be considered an extrinsic tracer, the 
${ }^{65} \mathrm{Cu}$ dose must be considered a dietary supplement. The stable isotope solution used in this project also contained enriched calcium (34.91 atoms percent enrichment of ${ }^{46} \mathrm{Ca}$ ) and provided an elemental calcium concentration of $20.4 \mu \mathrm{g} / \mathrm{mL}$ and a ${ }^{46} \mathrm{Ca}$ concentration of $7.1 \mu \mathrm{g} / \mathrm{mL}$.

The extrinsically labeled feeding was prepared by adding an accurately measured volume of the stable isotope solution to a plastic syringe containing about half of the feeding to be labeled. After the extrinsic ${ }^{70} \mathrm{Zn}$ and ${ }^{65} \mathrm{Cu}$ were allowed to equilibrate for 2 to $3 \mathrm{~h}$ with dietary (or intrinsic) zinc and copper, the labeled portion of the feeding was given to the infant by nasogastric tube. That syringe was then filled with the remaining unlabeled portion of the feeding and the feeding completed.

Analytical methods. Methods for determination of dietary fat, nitrogen, zinc, and copper; fecal fat and nitrogen; and urinary nitrogen, creatinine, zinc, and copper have been previously described (12).

Fecal zinc and copper isotopes were determined by inductively coupled plasma mass spectrometry (ICP-MS; Elan Model 250 System, SCIEX, Inc., Thornhill, Ontario, Canada) as previously described (13). For zinc, an in vitro isotope dilution technique was used in which an aliquot of the pooled fecal homogenate was spiked with ${ }^{67} \mathrm{Zn}$ before acid digestion, and then analyzed for ${ }^{67} \mathrm{Zn} /{ }^{68} \mathrm{Zn}$ and ${ }^{70} \mathrm{Zn} /{ }^{68} \mathrm{Zn}$ ratios. For copper, the ${ }^{65} \mathrm{Cu} /{ }^{63} \mathrm{Cu}$ ratio was measured in an aliquot of fecal homogenate that had been subjected to acid digestion. Total fecal copper was determined with atomic absorption spectrophotometry (Perkin Elmer model 5000, Perkin-Elmer Corp, Norwalk, CT).

Data analysis. Net nutrient absorption was calculated from standard nutritional balance data as the difference between dietary nutrient intake and fecal nutrient excretion during the balance period. Similarly, net nutrient retention was calculated from those data as the difference between dietary nutrient intake and the sum of fecal and urinary nutrient excretion during the balance period. These values were divided by the dietary nutrient intake and multiplied by $100 \%$ to obtain the percent net absorption and percent net retention, respectively. To express intake and output measurements on a per $\mathrm{kg}$ body wt per day basis, nutritional balance data from the $72-\mathrm{h}$ period were divided by three times the average body wt during the balance study interval.

The fractional absorption of the extrinsic ${ }^{70} \mathrm{Zn}$ and ${ }^{65} \mathrm{Cu}$ doses were calculated as previously described $(4,13,14)$ (see Appendix). Assuming that the absorption of dietary zinc and copper was equal to the absorption of the extrinsic tag, the true amount of absorbed dietary zinc and copper was calculated by multiplying the dietary intake by the fractional absorption of the stable isotope dose. Endogenous fecal loss was calculated as the difference between total fecal mineral content and the estimated amount contributed by unabsorbed dietary mineral and unabsorbed stable isotope dose (see Appendix). The estimated amount of unabsorbed dietary mineral was greater than the actual amount of total fecal mineral content in 16 zinc balances and nine copper balances, resulting in a negative value for endogenous fecal mineral loss. These studies could not be distinguished from the other balance studies on the basis of the characteristics listed in Table 1; they were not included in the calculation of endogenous fecal mineral loss. In addition, net mineral absorption equals the difference between true mineral absorption and endogenous fecal mineral loss. Therefore, net mineral absorption would be negative if the estimated endogenous fecal mineral loss was greater than the true mineral absorption (see Appendix).

Statistical analyses of the data were performed with the analytical software, including Statistical Analysis System, of the CLINFO Computer System, Clinical Research Center, Yale University School of Medicine. Comparison between feeding groups were performed with analysis of variance with Dunnett's and Newman-Keuls multiple comparison tests. The data from infants studied twice were compared with paired $t$ tests. Univariate linear regression analysis was used to examine the relationship between measures of zinc and copper absorption obtained with an extrin- sic stable isotopic tag and measures obtained with standard nutrient balance techniques. The SE of an estimated value of the percentage of ${ }^{70} \mathrm{Zn}$ absorption for a new value of the percentage of net zinc absorption was calculated according to Zar (15); similar determinations were made for the percentage of ${ }^{65} \mathrm{Cu}$ absorption given the percentage of net copper absorption, true zinc absorption given net zinc absorption, and true copper absorption given net copper absorption. In addition, univariate linear regression and multiple linear regression using the stepwise regression procedure were used to examine the relationship between mineral availability and dietary zinc and copper intake $(\mu \mathrm{g} / \mathrm{kg} / \mathrm{d})$, percentages of net fat and nitrogen absorption, postnatal age (d), postconceptional age (d), and average daily wt gain $(\mathrm{g} / \mathrm{kg} / \mathrm{d})$ in the 33 balance studies performed with PF. These analyses were not done with the balance studies performed with the other three diets due to their small sample sizes. Variables entered the stepwise regression model only if they met the 0.15 significance level. Data are expressed as mean $\pm \mathrm{SD}$.

\section{RESULTS}

Clinical profile. Fifty nutritional balance studies were performed in the 41 study subjects. Thirty-eight studies were performed while infants were formula-fed; 33 studies were done while infants received PF, and five studies were done while infants received TF. Twelve nutritional balance studies were performed while infants were fed with human milk; seven studies were done in seven infants receiving PTHM, and five studies were done in five infants receiving F-PTHM.

Table 1 summarizes the characteristics of the study subjects and of a number of study parameters according to diet during the balance study. For the purposes of all but the paired data analyses, each of the studies has been treated independently. There were no significant differences between the groups for gestational age, birth wt, and postnatal and postconceptional age at the onset of the balance period. Significant differences were noted in average body wt during the study between TF-fed infants and infants receiving each of the other feedings and in average daily wt gain between PF- and TF-fed infants. The average daily intake of TF was significantly greater than the intake of each of the other feedings and the average daily intake of PTHM was significantly greater than the intake of PF and F-PTHM. Similarly, the average daily urinary output was significantly greater by the TF-fed infants than by infants receiving each of the other feedings; the average daily urinary output was also significantly different between the PF- and PTHM-fed infants and between PTHM- and F-PTHM-fed infants. PF-fed infants excreted more creatinine than infants receiving the other diets. No differences were noted between the groups in the average transit time or the total wt of the fecal collection.

Nutritional balance studies were performed twice on nine infants, birth wt $1121 \pm 39 \mathrm{~g}$ and gestational age of $28.8 \pm 0.4$ wk. Of these infants, three received PF during the first and second balance studies; three received PF and then TF; one received PTHM and then F-PTHM; one received F-PTHM and then PTHM; and one received F-PTHM and then TF. The first study was performed at $19.0 \pm 6.0 \mathrm{~d}$ and the second study at $37.8 \pm 5.3 \mathrm{~d}$ postnatally; postconceptional ages of $221.2 \pm 10.2$ and $240.0 \pm 8.9 \mathrm{~d}$, respectively. During the studies the infants weighed an average of $1255 \pm 110$ versus $1852 \pm 90 \mathrm{~g}$ and gained $22.4 \pm 7.0$ versus $21.9 \pm 8.0 \mathrm{~g} / \mathrm{kg} / \mathrm{d}$. There were no significant differences between the first and second study in the average daily intake $(178.1 \pm 22.8$ versus $152.8 \pm 8.9 \mathrm{~mL} / \mathrm{kg} / \mathrm{d})$; urinary output $(82.8 \pm 21.3$ versus $62.4 \pm 10.4 \mathrm{~mL} / \mathrm{kg} / \mathrm{d})$; urinary creatinine excretion $(13.3 \pm 4.3$ versus $10.2 \pm 4.2 \mathrm{mg} / \mathrm{kg} / \mathrm{d})$; average transit time $(29.4 \pm 11.8$ versus $29.7 \pm 15.4 \mathrm{~h})$; and total wt of the fecal collection $(31.0 \pm 11.6$ versus $22.2 \pm 4.9 \mathrm{~g})$.

Fat balance. Dietary fat intake differed between PF- and PTHM-fed infants and fecal fat excretion differed between TFfed infants and infants receiving each of the other feedings (Table 
Table 1. Clinical profile of subjects by study diet

\begin{tabular}{|c|c|c|c|c|}
\hline & $\begin{array}{c}\text { Premature } \\
\text { formula }\end{array}$ & PTHM & F-PTHM & $\begin{array}{c}\text { Term } \\
\text { formula }\end{array}$ \\
\hline No. infants (studies) & $30(33)$ & $7(7)$ & $5(5)$ & $5(5)$ \\
\hline Gestational age (wk) & $\begin{array}{c}30.1 \pm 1.8^{*} \\
(27-34)\end{array}$ & $\begin{array}{c}29.0 \pm 1.8 \\
(26-31)\end{array}$ & $\begin{array}{c}29.0 \pm 2.1 \\
(26-31)\end{array}$ & $\begin{array}{c}29.4 \pm 1.9 \\
(28-32)\end{array}$ \\
\hline Birth wt (g) & $\begin{array}{c}1295 \pm 238 \\
(720-1660)\end{array}$ & $\begin{array}{c}1189 \pm 308 \\
(760-1600)\end{array}$ & $\begin{array}{c}1082 \pm 175 \\
(880-1270)\end{array}$ & $\begin{array}{c}1284 \pm 220 \\
(1090-1660)\end{array}$ \\
\hline Postnatal age (d) & $\begin{array}{c}20.2 \pm 11.5 \\
(4-48)\end{array}$ & $\begin{array}{c}33.1 \pm 27.0 \\
(9-83)\end{array}$ & $\begin{array}{c}29.2 \pm 7.7 \\
(18-37)\end{array}$ & $\begin{array}{c}32.6 \pm 10.8 \\
(15-44)\end{array}$ \\
\hline Postconceptional age (d) & $\begin{array}{c}230.0 \pm 11.1 \\
(208-251)\end{array}$ & $\begin{array}{c}236.1 \pm 19.8 \\
(205-265)\end{array}$ & $\begin{array}{c}232.2 \pm 11.4 \\
(218-245)\end{array}$ & $\begin{array}{c}238.4 \pm 10.7 \\
(229-255)\end{array}$ \\
\hline Average wt (g) & $1524 \pm 224 \dagger$ & $1608 \pm 295 \dagger$ & $1407 \pm 182 \dagger$ & $1897 \pm 58$ \\
\hline During study & $(1102-1950)$ & $(1117-1958)$ & $(1206-1704)$ & $(1804-1946)$ \\
\hline Average wt gain $(\mathrm{g} / \mathrm{kg} / \mathrm{d})$ & $\begin{array}{l}23.6 \pm 5.1 \dagger \\
(13.6-36.6)\end{array}$ & $\begin{array}{l}18.0 \pm 5.7 \\
(13.8-29.1)\end{array}$ & $\begin{array}{l}25.2 \pm 9.3 \\
(10.9-36.5)\end{array}$ & $\begin{array}{c}16.0 \pm 5.4 \\
(9.7-20.9)\end{array}$ \\
\hline Intake $(\mathrm{mL} / \mathrm{kg} / \mathrm{d})$ & $\begin{array}{c}156.0 \pm 12.6+\ddagger \\
(128-208)\end{array}$ & $\begin{array}{c}169.5 \pm 9.5 \dagger \\
(159-186)\end{array}$ & $\begin{array}{c}143.8 \pm 4.9 \dagger \neq \\
(139-151)\end{array}$ & $\begin{array}{c}196.0 \pm 15.1 \\
(178-213)\end{array}$ \\
\hline Urine output $(\mathrm{mL} / \mathrm{kg} / \mathrm{d})$ & $\begin{array}{l}60.5 \pm 10.8 \dagger \ddagger \\
(24.4-80.5)\end{array}$ & $\begin{array}{l}77.7 \pm 10.4 \dagger \\
(59.4-87.8)\end{array}$ & $\begin{array}{l}59.1 \pm 12.6+\ddagger \\
(45.7-79.8)\end{array}$ & $\begin{array}{l}98.8 \pm 13.6 \\
(87.6-118.4)\end{array}$ \\
\hline Urinary creatinine $(\mathrm{mg} / \mathrm{kg} / \mathrm{d})$ & $\begin{array}{c}14.0 \pm 2.6 \\
(8.4-18.8)\end{array}$ & $\begin{array}{l}7.8 \pm 1.6 \S \\
(4.4-9.4)\end{array}$ & $\begin{array}{l}8.8 \pm 3.9 \S \\
(4.2-14.4)\end{array}$ & $\begin{array}{l}9.3 \pm 2.0 \S \\
(6.2-11.4)\end{array}$ \\
\hline Transit time $(\mathrm{h})$ & $\begin{array}{l}29.4 \pm 12.2 \\
(11.5-57.2)\end{array}$ & $\begin{array}{c}21.8 \pm 12.2 \\
(6.6-45.0)\end{array}$ & $\begin{array}{l}38.6 \pm 17.7 \\
(19.5-64.5)\end{array}$ & $\begin{array}{r}20.9 \pm 13.4 \\
(7.2-39.0)\end{array}$ \\
\hline Total fecal wt (g) & $\begin{array}{l}32.3 \pm 13.1 \\
(13.7-75.4)\end{array}$ & $\begin{array}{l}25.6 \pm 8.8 \\
(16.2-35.3)\end{array}$ & $\begin{array}{l}23.5 \pm 5.2 \\
(19.9-32.6)\end{array}$ & $\begin{array}{l}36.3 \pm 9.8 \\
(26.2-49.3)\end{array}$ \\
\hline
\end{tabular}

$*$ Mean \pm SD (range).

$\dagger p<0.05$ versus TF.

$\$ p<0.05$ versus PTHM.

$\S p<0.05$ versus $\mathrm{PF}$.

Table 2. Fat and nitrogen balance data by study diet

\begin{tabular}{|c|c|c|c|c|}
\hline & $\begin{array}{c}\text { Premature } \\
\text { formula } \\
(n=33)\end{array}$ & $\begin{array}{l}\text { PTHM } \\
(n=7)\end{array}$ & $\begin{array}{c}\text { F-PTHM } \\
(n=5)\end{array}$ & $\begin{array}{c}\text { Term } \\
\text { formula } \\
(n=5)\end{array}$ \\
\hline \multicolumn{5}{|l|}{ Fat $(\mathrm{g} / \mathrm{kg} / \mathrm{d})$} \\
\hline Intake & $6.34 \pm 0.52^{*}$ & $5.17 \pm 2.26 \dagger$ & $5.37 \pm 1.26$ & $7.53 \pm 0.75$ \\
\hline Fecal excretion & $0.81 \pm 0.40 \ddagger$ & $0.53 \pm 0.54 \ddagger$ & $0.60 \pm 0.26 \ddagger$ & $1.33 \pm 0.61$ \\
\hline Net absorption & $5.52 \pm 0.66$ & $4.64 \pm 2.09$ & $4.77 \pm 1.51$ & $6.20 \pm 1.03$ \\
\hline$\%$ Net absorption & $87.1 \pm 6.4$ & $89.1 \pm 9.2$ & $86.9 \pm 11.1$ & $82.1 \pm 8.8$ \\
\hline \multicolumn{5}{|l|}{ Nitrogen $(\mathrm{mg} / \mathrm{kg} / \mathrm{d})$} \\
\hline Intake & $575.7 \pm 59.0$ & $443.5 \pm 68.9 \dagger$ & $528.5 \pm 55.1$ & $478.6 \pm 47.2 \dagger$ \\
\hline Fecal excretion & $78.9 \pm 23.8$ & $55.9 \pm 14.9 \dagger$ & $74.5 \pm 12.9$ & $58.5 \pm 11.6$ \\
\hline Urinary excretion & $93.3 \pm 25.6$ & $100.0 \pm 43.8$ & $101.5 \pm 35.3$ & $75.6 \pm 4.6$ \\
\hline Net retention & $403.6 \pm 51.4$ & $288.3 \pm 54.0 \dagger$ & $352.5 \pm 33.1$ & $344.5 \pm 46.4 \dagger$ \\
\hline$\%$ Net absorption & $86.3 \pm 4.1$ & $87.3 \pm 3.5$ & $85.9 \pm 2.2$ & $87.6 \pm 3.1$ \\
\hline$\%$ Net retention & $70.1 \pm 4.9$ & $64.8 \pm 8.4$ & $66.9 \pm 5.3$ & $71.8 \pm 3.4$ \\
\hline
\end{tabular}

$*$ Mean $\pm \mathrm{SD}$.

$\uparrow p<0.05$ versus PF.

$\ddagger p<0.05$ versus TF.

2). However, no significant differences were noted between the four feeding groups in the net amount of fat absorbed or in the percent net fat absorption. In addition, the percent net fat absorption and the net amount of fat absorbed did not increase with increasing postnatal age in the infants studied twice. net fat absorption was $87.2 \pm 7.6$ versus $86.8 \pm 9.7 \%$ and $5.5 \pm 0.8$ versus $6.1 \pm 0.9 \mathrm{~g} / \mathrm{kg} / \mathrm{d}$ for the first and second studies, respectively.

Nitrogen balance. Dietary nitrogen intake differed between PF- and PTHM-fed and PF- and TF-fed infants and fecal nitrogen excretion differed between PF- and PTHM-fed infants (Table 2). The net amount of nitrogen retained by PTHM- and TF-fed infants was significantly lower than that by PF-fed infants. However, the percentages of net dietary nitrogen absorption and retention were similar between the four feeding groups. The percent net nitrogen absorption did not change between the first and second study in the infants studied twice $(87.1 \pm 2.9$ versus $87.9 \pm 2.2 \%)$. However, the percent net nitrogen retention significantly increased, from $67.2 \pm 6.4$ to $72.2 \pm 4.8 \%$, corresponding with a significant decrease in urinary nitrogen excretion, from $108.3 \pm 33.3$ to $79.9 \pm 12.5 \mathrm{mg} / \mathrm{kg} / \mathrm{d}$.

Zinc balance. Dietary zinc intake and fecal zinc excretion by PTHM-fed infants were significantly less than zinc intake and excretion by infants given each of the other feedings (Table 3). Net zinc absorption and retention were similar between the four feeding groups. However, the percent net zinc absorption was significantly higher in the PTHM-fed infants than in infants fed formula, and the percent net zinc retention was significantly 
Table 3. Zinc balance data by study diet

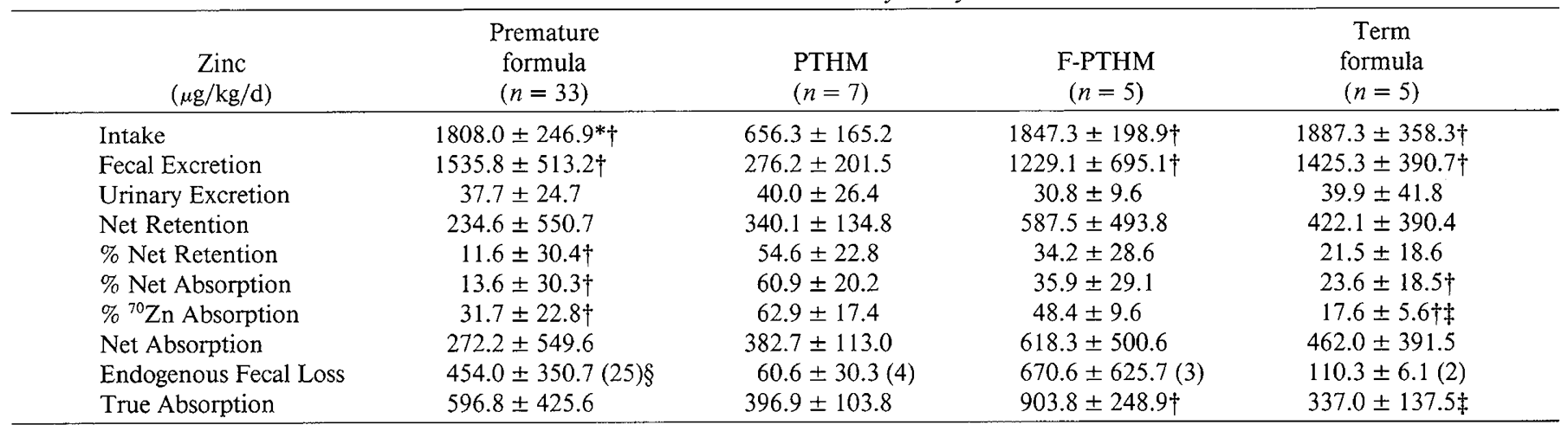

* Mean \pm SD.

$\dagger p<0.05$ versus PTHM.

$\ddagger p<0.05$ versus F-PTHM.

$\S(n)$.

higher in the PTHM-fed infants than in PF-fed infants. Similar to net zinc absorption, the percent ${ }^{70} \mathrm{Zn}$ absorption was significantly higher by the PTHM-fed infants than by formula-fed infants, and true zinc absorption was similar. F-PTHM-fed infants had a significantly higher percent ${ }^{70} \mathrm{Zn}$ absorption than TFfed infants and a significantly greater true zinc absorption than PTHM-fed and TF-fed infants. No significant differences in average zinc balance data were observed between the first and second studies.

Estimates of endogenous fecal zinc loss could only be calculated in 25 of the 33 studies performed with $\mathrm{PF}$, in four studies with PTHM, in three studies with F-PTHM, and in two studies with TF. No significant differences of these estimates were noted between feeding groups. Values for endogenous fecal zinc loss could only be calculated from three of the nine infants studied twice; no differences were noted between the first and second studies.

Univariate linear regression analysis demonstrated that the percent ${ }^{70} \mathrm{Zn}$ absorption correlated significantly $(p=0.0001)$ with the percent net zinc absorption (Fig. 1) and that true zinc absorption correlated significantly $(p=0.0001)$ with net zinc absorption (Fig. 2). In addition, the percent net zinc absorption was significantly related to endogenous fecal zinc loss $(Y=35.66$ $-0.05 \mathrm{X}, r=-0.632, p=0.0001, n=34$ ) and endogenous fecal zinc loss was significantly related to daily fecal zinc excretion ( $Y$ $=-128.63+0.37 \mathrm{X}, r=0.617, p=0.001, n=34$ ).

In an effort to reduce variability that might be associated with different formulas and because the percentages of net zinc absorption and of ${ }^{70} \mathrm{Zn}$ absorption were significantly higher with PTHM and F-PTHM than with the formulas, only data from the 33 studies performed with PF were subjected to additional analyses with univariate linear regression (Table 5) and multiple linear regression using the stepwise regression procedure (Table 6 ). The percent ${ }^{70} \mathrm{Zn}$ absorption and true zinc absorption were significantly related to postconceptional age and average daily wt gain, and approached a significant association with postnatal age. Significant univariate relationships were also observed between daily dietary zinc intake and the average daily wt gain and the percentages of net zinc absorption and retention and the amount of net zinc absorption and retention. Postnatal age and postconceptional age were not significantly correlated with net zinc absorption or retention measurements. Interactions between the percent net fat absorption and net zinc absorption and retention measurements and endogenous fecal zinc loss approached significance.

Significant correlations determined with multiple linear regression using the stepwise regression procedure between the effects of average daily wt gain, postnatal age, postconceptional age, dietary zinc and copper intake, percentage of net nitrogen ab-

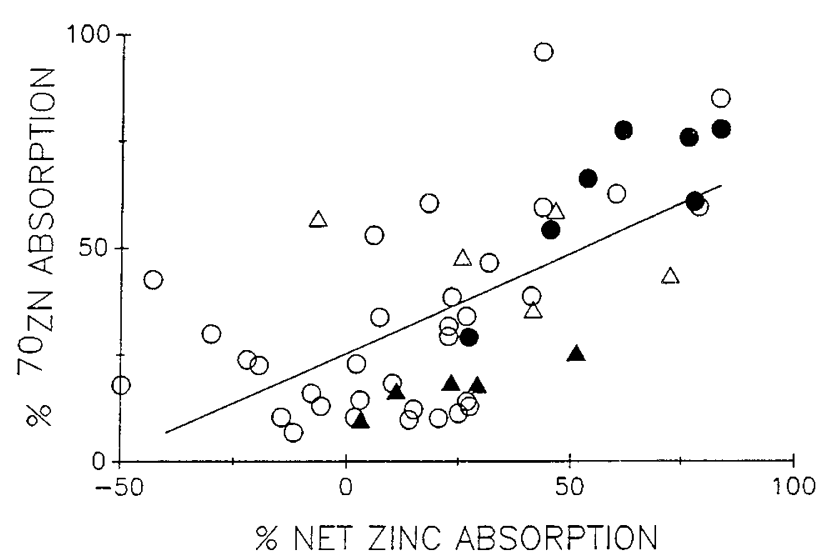

Fig. 1. Univariate linear regression analysis demonstrates a significant correlation between the percentages of ${ }^{70} \mathrm{Zn}$ absorption and net zinc absorption ( $\mathrm{Y}=25.35+0.47 \mathrm{X}, r=0.637, p=0.0001$ ). The $\mathrm{SE}$ of estimating $Y_{i}$ at $X_{i}$ ranges from \pm 18.5 if the new $X_{i}$ is close to the mean to \pm 19.2 if $X_{i}$ approaches the lowest or highest values found in this investigation. Premature formula $(n=33,0) ; \operatorname{PTHM}(n=7, \bullet)$; fortified$\operatorname{PTHM}(\mathrm{n}=5, \triangle)$; and term formula $(\mathrm{n}=5, \mathbf{\Delta})$.

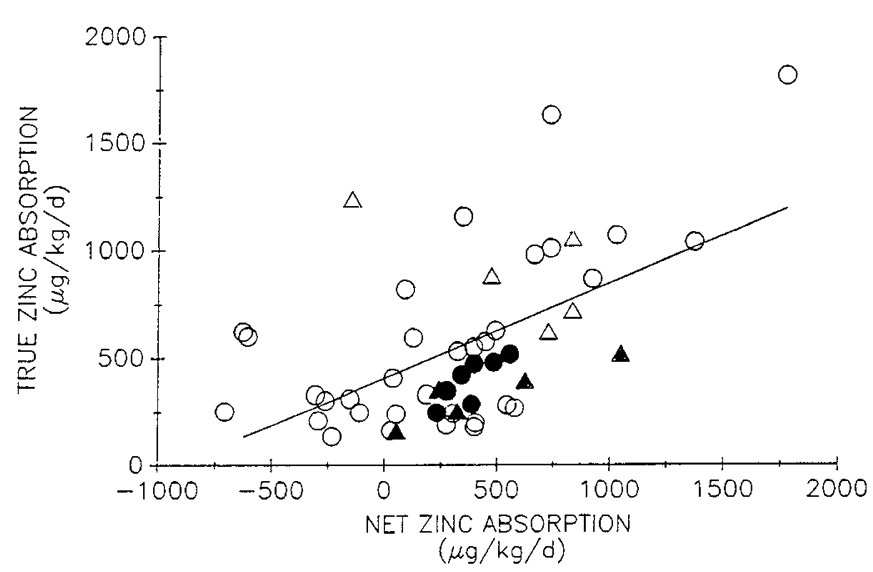

Fig. 2. Univariate linear regression analysis demonstrates a significant correlation between true zinc absorption and net zinc retention ( $\mathrm{Y}=$ $408.63+0.44 \mathrm{X}, r=0.556, p=0.0001$ ). The standard error of estimating $Y_{i}$ at $X_{i}$ ranges from \pm 320 if $X_{i} \sim \bar{X}$ to \pm 350 if $X_{i}$ approaches the lowest or highest values found in this investigation. Premature formula $(n=33,0)$; PTHM $(n=7,0)$; fortified-PTHM $(n=5, \Delta)$; and term formula $(n=5, \mathbf{\Delta})$. 
Table 4. Copper balance data by study diet

\begin{tabular}{|c|c|c|c|c|}
\hline $\begin{array}{c}\text { Copper } \\
(\mu \mathrm{g} / \mathrm{kg} / \mathrm{d})\end{array}$ & $\begin{array}{c}\text { Premature } \\
\text { formula } \\
(n=33)\end{array}$ & $\begin{array}{l}\text { PTHM } \\
(n=7)\end{array}$ & $\begin{array}{c}\text { F-PTHM } \\
(n=5)\end{array}$ & $\begin{array}{c}\text { Term } \\
\text { formula } \\
(n=5)\end{array}$ \\
\hline Intake & $188.9 \pm 39.4 * \dagger$ & $86.6 \pm 28.2$ & $151.7 \pm 34.4 \dagger$ & $194.2 \pm 27.5 \dagger \ddagger$ \\
\hline Urinary excretion & $8.6 \pm 4.0$ & $6.1 \pm 3.2$ & $5.3 \pm 1.8$ & $5.5 \pm 2.8$ \\
\hline Net retention & $22.8 \pm 41.3$ & $44.2 \pm 14.6$ & $51.9 \pm 12.7$ & $37.3 \pm 51.2$ \\
\hline$\%$ Net retention & $10.8 \pm 20.7 \dagger t$ & $52.8 \pm 14.4$ & $35.0 \pm 9.5$ & $17.7 \pm 24.2 \dagger$ \\
\hline Net absorption & $31.4 \pm 41.3$ & $50.4 \pm 16.0$ & $57.1 \pm 12.4$ & $42.8 \pm 51.6$ \\
\hline Endogenous fecal loss & $52.4 \pm 31.3 \dagger(27)$ & $13.9 \pm 18.8(5)$ & $30.8 \pm 26.6(5)$ & $38.9 \pm 30.8(3)$ \\
\hline True absorption & $73.4 \pm 43.9(32)$ & $59.8 \pm 29.7$ & $88.0 \pm 31.9$ & $51.4 \pm 15.4$ \\
\hline
\end{tabular}

* Mean \pm SD.

$\dagger p<0.05$ versus PTHM.

$\ddagger p<0.05$ versus F-PTHM.

$\S(n)$.

sorption, and percentage of net fat absorption and measures of zinc absorption and retention are shown in Table 6 . Average daily wt gain, percent net fat absorption, and dietary zinc and copper intakes accounted for about $57 \%$ of the variability in the percentages of net zinc absorption $\left(r^{2}=0.577\right)$ and retention $\left(r^{2}\right.$ $=0.560)$ and in the amount of net zinc absorption $\left(r^{2}=0.574\right)$ and retention $\left(r^{2}=0.554\right)$. Average daily wt gain, the percent net fat absorption, and postnatal age entered the model describing endogenous fecal zinc loss and accounted for $34.4 \%$ of the variability $\left(r^{2}=0.344\right)$. Of the variables tested, only average daily wt gain met the 0.15 significance level for entry into the model describing the percent of ${ }^{70} \mathrm{Zn}$ absorption and true zinc absorption, accounting for about $21 \%$ of the variability of those measures. Postconceptional age and nitrogen absorption did not meet the significance level for entry into any of these models.

Copper balance. Dietary copper intake and fecal copper excretion by PTHM-fed infants were significantly less than copper intake and fecal excretion by infants given each of the other feedings (Table 4). Dietary copper intake by F-PTHM-fed infants was significantly less than copper intake by TF-fed infants. Fecal copper excretion from infants fed F-PTHM was significantly less than from formula-fed infants. Although net copper absorption and retention and true copper absorption were similar between the four feeding groups, the percent net copper absorption and retention was significantly higher in PTHM-fed infants than in infants fed formula; the percent net copper absorption and retention was also higher in F-PTHM-fed infants than in PF-fed infants. The percent ${ }^{65} \mathrm{Cu}$ absorption by PTHM-fed infants was significantly greater than by formula-fed infants and the percent ${ }^{65} \mathrm{Cu}$ absorption by F-PTHM-fed infants was significantly greater than by TF-fed infants. Due to sample contamination before inductively coupled plasma mass spectrometry analysis, ${ }^{65} \mathrm{Cu}$ absorption could only be determined in 32 of the 33 PF balances. No significant differences in average copper balance data were observed between the first and second studies.

Estimates of endogenous fecal copper loss could only be calculated in 27 of the 33 studies performed with PF, in five studies with PTHM, in five studies with F-PTHM, and in three studies with TF. Endogenous fecal copper loss was significantly lower in PTHM-fed infants than in PF-fed infants. Values for endogenous fecal copper loss could only be calculated from four of the nine infants studied twice; no differences were noted between the first and second studies.

Univariate linear regression analysis demonstrated that the percent ${ }^{65} \mathrm{Cu}$ absorption correlated significantly $(p=0.0001)$ with the percent net copper absorption (Fig. 3) and that true copper absorption correlated significantly $(p=0.001)$ with net copper absorption (Fig. 4). Furthermore, the percent net copper absorption was significantly related to endogenous fecal copper

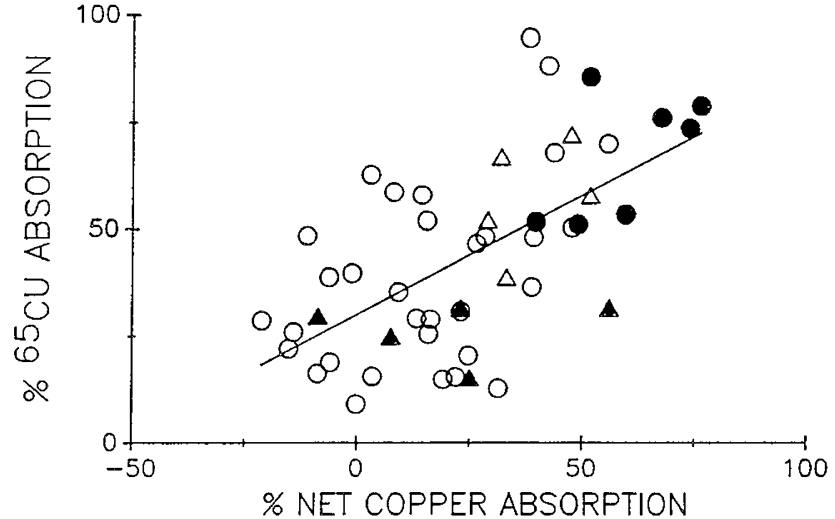

Fig. 3. Univariate linear regression analysis demonstrates a significant correlation between the percentages of ${ }^{65} \mathrm{Cu}$ absorption and net copper absorption ( $\mathrm{Y}=30.05+0.56 \mathrm{X}, r=0.614, p=0.0001)$. The SE of estimating $Y_{i}$ at $X_{i}$ ranges from \pm 18.0 if $X_{i} \sim \bar{X}$ to \pm 19.0 if $X_{i}$ approaches the lowest or highest values found in this investigation. Premature formula $(n=32,0)$; PTHM $(n=7, \bullet)$; fortified-PTHM $(n$ $=5, \Delta)$; and term formula $(n=5, \mathbf{\Delta})$.

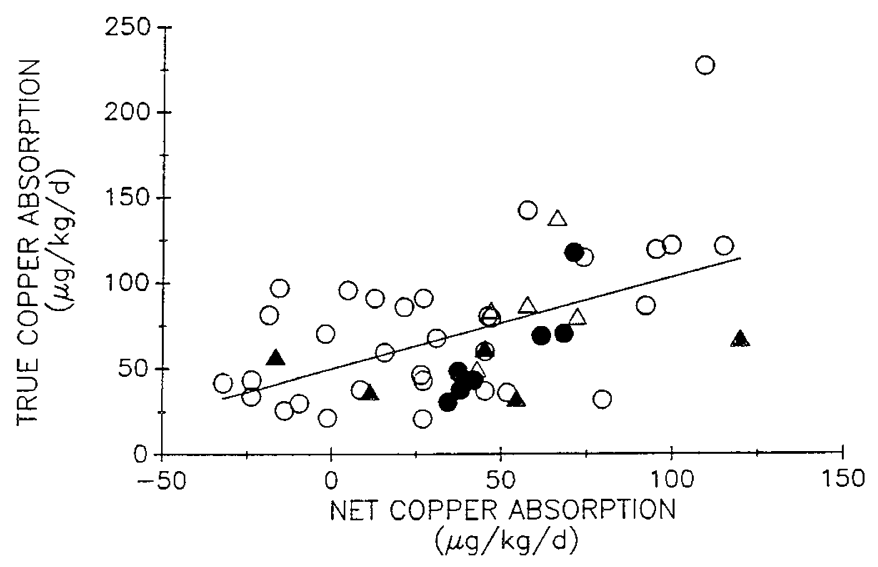

Fig. 4. Univariate linear regression analysis demonstrates a significant correlation between true copper absorption and net copper retention ( $Y$ $=50.39+0.53 \mathrm{X}, r=0.522, p=0.001)$. The SE of estimating $\mathrm{Y}_{\mathrm{i}}$ at $\mathrm{X}_{\mathrm{i}}$ from \pm 34.0 if $X_{i} \sim \bar{X}$ to \pm 35.8 if $X_{i}$ approaches the lowest or highest values found in this investigation. Premature formula $(n=32,0)$; PTHM $(n=7,0)$; fortified-PTHM $(n=5, \Delta)$; and term formula $(n=5, \mathbf{\Delta})$. 
loss ( $\mathrm{Y}=38.87-0.40 \mathrm{X}, r=-0.507, p=0.0008, n=40)$ and endogenous fecal copper loss was significantly related to daily fecal copper excretion ( $\mathrm{Y}=6.16+0.27 \mathrm{X}, r=0.500, p=0.001$, $n=40$ ).

As noted above, only the data from the 33 studies performed with PF were subjected to additional analyses with univariate linear regression (Table 5) and multiple linear regression using the stepwise regression procedure (Table 6). The percent ${ }^{65} \mathrm{Cu}$ absorption was significantly related to postconceptional age and average daily wt gain, but not to postnatal age or daily dietary copper intake. True copper absorption was significantly related to average daily wt gain and net nitrogen absorption; interactions with postconceptional age and the percent net fat absorption approached significance. Average daily wt gain and the percentages of net fat absorption and net nitrogen absorption were found to be significantly associated with the percentages and the amounts of net copper absorption and retention. Dietary copper and zinc intake were significantly related to net copper absorp- tion and retention; an interaction between dietary copper intake and the percentages of net copper absorption and retention approached significance. Postnatal age and postconceptional age were not significantly correlated with net copper absorption or retention measurements. Endogenous fecal copper loss was not associated with any of the variables tested.

Significant correlations determined with multiple linear regression using the stepwise regression procedure between the effects of the variables tested above and measures of copper absorption and retention are shown in Table 6. Average daily wt gain and the percent net fat absorption accounted for 40 to $52 \%$ of the variability in the percentages of net copper absorption $\left(r^{2}=\right.$ $0.441)$ and retention $\left(r^{2}=0.398\right)$ and in the amount of net copper absorption $\left(r^{2}=0.519\right)$ and retention $\left(r^{2}=0.475\right)$. Dietary copper intake accounted for an additional $3.9 \%$ of the variability in net copper absorption. Average daily wt gain and the percent net fat absorption accounted for $33.1 \%$ of the variability $\left(r^{2}=0.331\right)$ in true copper absorption and average daily

Table 5. Analyses of zinc and copper balance data: univariate linear regression*

\begin{tabular}{lccccccc}
\hline & $\begin{array}{c}\text { Postnatal } \\
\text { age }\end{array}$ & $\begin{array}{c}\text { Postconceptional } \\
\text { age }\end{array}$ & $\begin{array}{c}\text { Zinc } \\
\text { intake }\end{array}$ & $\begin{array}{c}\text { Copper } \\
\text { intake }\end{array}$ & $\begin{array}{c}\text { Wt } \\
\text { gain }\end{array}$ & $\begin{array}{c}\text { Fat } \\
\text { absorption }\end{array}$ & $\begin{array}{c}\text { Nitrogen } \\
\text { absorption }\end{array}$ \\
\hline Zinc & & & & & & & \\
\% Net absorption & $0.340 \dagger$ & 0.397 & 0.045 & 0.869 & 0.008 & 0.084 & 0.198 \\
\% Net retention & 0.312 & 0.408 & 0.045 & 0.860 & 0.009 & 0.092 & 0.210 \\
Net absorption & 0.267 & 0.244 & 0.035 & 0.675 & 0.004 & 0.096 & 0.173 \\
Net retention & 0.241 & 0.248 & 0.040 & 0.688 & 0.005 & 0.108 & 0.184 \\
\% ${ }^{7}$ Zn absorption & 0.059 & 0.032 & 0.746 & 0.474 & 0.008 & 0.903 & 0.441 \\
Endogenous fecal loss & 0.278 & 0.987 & 0.278 & 0.661 & 0.154 & 0.072 & 0.496 \\
True absorption & 0.078 & 0.044 & 0.483 & 0.922 & 0.006 & 0.595 & 0.402 \\
Copper & & & & & & & \\
\% Net absorption & 0.329 & 0.158 & 0.184 & 0.079 & 0.003 & 0.018 & 0.004 \\
\% Net retention & 0.242 & 0.157 & 0.190 & 0.068 & 0.004 & 0.027 & 0.004 \\
Net absorption & 0.276 & 0.150 & 0.035 & 0.006 & 0.001 & 0.007 & 0.003 \\
Net retention & 0.224 & 0.132 & 0.050 & 0.010 & 0.002 & 0.012 & 0.004 \\
\% ${ }^{65}$ Cu absorption & 0.520 & 0.025 & 0.559 & 0.453 & 0.024 & 0.263 & 0.106 \\
Endogenous fecal loss & 0.626 & 0.724 & 0.538 & 0.659 & 0.915 & 0.317 & 0.447 \\
True absorption & 0.445 & 0.078 & 0.368 & 0.215 & 0.005 & 0.096 & 0.048 \\
\hline
\end{tabular}

* Only data from the 33 balance studies performed with premature formula analyzed.

$\dagger p$ value from univariate linear regression analysis $(\mathrm{Y}=\mathrm{aX}+\mathrm{b})$.

Table 6. Analyses of zinc and copper balance data*: multiple linear regression using stepwise regression procedure

\begin{tabular}{|c|c|c|c|c|c|c|c|c|}
\hline & $\begin{array}{l}\mathrm{Wt} \\
\text { gain }\end{array}$ & $\begin{array}{c}\text { Fat } \\
\text { absorption }\end{array}$ & $\begin{array}{l}\text { Nitrogen } \\
\text { absorption }\end{array}$ & $\begin{array}{l}\text { Zinc } \\
\text { intake }\end{array}$ & $\begin{array}{l}\text { Copper } \\
\text { intake }\end{array}$ & $\begin{array}{c}\text { Postconceptional } \\
\text { age }\end{array}$ & $\begin{array}{c}\text { Postnatal } \\
\text { age }\end{array}$ & $p$ value $\dagger$ \\
\hline \multicolumn{9}{|l|}{ Zinc } \\
\hline$\%$ Net absorption & $0.206 \ddagger$ & 0.078 & NS§ & 0.117 & 0.179 & NS & NS & 0.0001 \\
\hline Net absorption & 0.237 & 0.063 & NS & 0.128 & 0.146 & NS & NS & 0.0001 \\
\hline Net retention & 0.230 & 0.059 & NS & 0.123 & 0.142 & NS & NS & 0.0001 \\
\hline$\%^{70} \mathrm{Zn}$ absorption & 0.207 & NS & NS & NS & NS & NS & NS & 0.008 \\
\hline \multicolumn{9}{|l|}{ Copper } \\
\hline$\%$ Net absorption & 0.255 & 0.186 & NS & NS & NS & NS & NS & 0.0002 \\
\hline$\%$ Net retention & 0.234 & 0.164 & NS & NS & NS & NS & NS & 0.0005 \\
\hline Net absorption & 0.287 & 0.231 & NS & NS & 0.039 & NS & NS & 0.0001 \\
\hline Net retention & 0.270 & 0.205 & NS & NS & NS & NS & NS & 0.0001 \\
\hline
\end{tabular}

* Only data from the 33 balance studies performed with premature formula analyzed.

$\dagger$ Overall significance of the regression equation when all significant variables were included.

$\ddagger$ Variability accounted for by tested variable (partial $r^{2}$ ).

$\S$ Variable did not enter model; significance level $>0.15$ (see text). 
wt gain and postconceptional age accounted for $23.3 \%$ of the variability $\left(r^{2}=0.233\right)$ in the percent ${ }^{65} \mathrm{Cu}$ absorption. Endogenous fecal copper loss was not significantly related to any of the variables tested by the stepwise linear regression procedure. Postnatal age, percent net nitrogen absorption, and dietary zinc intake did not meet the significance level for entry into any of these models.

\section{DISCUSSION}

It is often recommended that the enteral diet provided to VLBW infants should support wt gain and nutrient accretion at rates that approach intrauterine estimates $(1,2)$. Although determination of dietary nutrient absorption and retention with standard balance methodology provides a measure of nutrient availability, care must be taken to minimize sources of error during measurement of dietary input and collection of fecal and urinary output (3). In addition, standard balance methodology only measures net or apparent absorption and retention because it cannot distinguish endogenous fecal nutrient loss from the unabsorbed component of dietary nutrient. Although not immune from the nonrandom errors that occur in standard nutrient balance studies, the extrinsic tag approach with stable isotope methods permits a determination of true nutrient absorption $(10,11)$ and should permit estimates of endogenous fecal nutrient loss.

The intrauterine accretion rates of zinc and copper are about 250 and $51 \mu \mathrm{g} / \mathrm{kg} / \mathrm{d}$, respectively, during the 3rd trimester (1618). Previous reports (19-23) have demonstrated marked differences in the ability of VLBW infants to absorb dietary zinc and copper and in the ability of enteral nutrition to achieve the in utero accretion rates. Factors contributing to these reported differences include postnatal age $(19,21,22)$, postconceptional age (23), net fat and nitrogen absorption (20), and diet (formula, pooled pasteurized human milk, PTHM) (21). Our study was designed to compare measurements of dietary zinc and copper absorption obtained with both extrinsic stable isotopic tags and standard nutrient balance methods. We hoped that this investigation would demonstrate the actual ability of VLBW infants to absorb dietary zinc and copper and the influence of the type of diet, postnatal age, and postconceptional age on this ability.

We have found that growing VLBW infants who have no evidence of net fat or nitrogen malabsorption (Table 2) are, on average, in positive net zinc and copper balance (Tables 3 and 4). Net zinc and copper retention were similar with each diet and infants approached or exceeded the intrauterine accumulation rate for those minerals in the majority of the balance studies. These findings are similar to our previously reported results comparing PF and F-PTHM (12), and are consistent with the data of Mendleson et al. (21) and Tyrala (22). Our data are also in agreement with the observation by Voyer et al. (20) that net zinc balance became positive when net fat and nitrogen absorption exceeded $90 \%$.

Our data (Tables 3 and 4) demonstrated that the percentages of net zinc and copper absorption and retention were significantly higher from PTHM than from formula. Similarly, the percentages of ${ }^{70} \mathrm{Zn}$ and ${ }^{65} \mathrm{Cu}$ absorption were significantly higher from PTHM than from formula. The percentages of net zinc and copper absorption and retention and of ${ }^{70} \mathrm{Zn}$ and ${ }^{65} \mathrm{Cu}$ absorption from F-PTHM were similar to those of PTHM. In addition, the percent net copper absorption was significantly higher from FPTHM than from PF and ${ }^{70} \mathrm{Zn}$ and ${ }^{65} \mathrm{Cu}$ absorption were significantly higher from F-PTHM than from TF. Inasmuch as dietary zinc and copper intakes were much higher in the formula-fed infants than in the PTHM-fed infants and because net zinc and copper retentions were similar, our findings are consistent with studies that have shown a higher bioavailability of zinc $(18,24$, $25)$ and copper $(18,21)$ from human milk than from cow's milk or infant formulas. Furthermore, because true zinc absorption by F-PTHM-fed infants was significantly greater than by PTHMand TF-fed infants, our findings suggest that human milk may facilitate the absorption of the supplemental zinc and copper that is included in the powdered human milk fortifier.

Although we previously reported that ${ }^{70} \mathrm{Zn}$ absorption in VLBW infants was about $60 \%$ and was not influenced by diet (4), we were concerned about the accuracy of that conclusion because of the manner in which the ${ }^{70} \mathrm{Zn}$ had been administered. We believe that the current study design ensures that the extrinsic stable isotope dose has a chance to equilibrate with dietary mineral before a feeding. Therefore, the differences in ${ }^{70} \mathrm{Zn}$ and ${ }^{65} \mathrm{Cu}$ absorption observed with the different diets in this study should represent the affect of diet on the absorption of dietary mineral. Lower values of isotopic zinc absorption have been found in human adults when the extrinsic tag was ingested with food compared to ingestion in a postabsorptive state (25-28). Absorption of isotopic copper by human adults may be more variable; some investigators $(14,29,30)$ have reported that absorption is not decreased if the isotope is ingested with food, whereas others (31) report low values even in a postabsorptive state.

It has been suggested that the prolonged negative net zinc and copper balance observed by some investigators $(19,20,23)$ occurs largely because of immaturity of the gastrointestinal tract in the premature infant that fails to reabsorb the zinc and copper that is present in pancreatic and intestinal secretions, bile, and in discarded epithelial cells $(16,17,19,32,33)$. Our estimates of endogenous fecal loss of zinc and copper attempt to quantitate this loss and lend support to this explanation. Mean values were substantial and ranged from $60.6 \mu \mathrm{g} \mathrm{zinc} / / \mathrm{kg} / \mathrm{d}$ and $13.9 \mu \mathrm{g}$ copper $/ \mathrm{kg} / \mathrm{d}$ for PTHM-fed infants to $670.6 \mu \mathrm{g} \mathrm{zinc} / \mathrm{kg} / \mathrm{d}$ for FPTHM-fed infants and $52.4 \mu \mathrm{g}$ copper $/ \mathrm{kg} / \mathrm{d}$ for PF-fed infants. For comparison, endogenous fecal losses of zinc and copper can also be estimated by extrapolating the linear regression equation between net mineral absorption and dietary mineral intake to 0 intake; for PF, these estimates were about $1200 \mu \mathrm{g} \mathrm{zinc} / \mathrm{kg} / \mathrm{d}$ and about $60 \mu \mathrm{g}$ copper $/ \mathrm{kg} / \mathrm{d}$. Fecal losses of zinc and copper in parenterally fed VLBW infants who were achieving intrauterine rates of zinc and copper accumulation have been shown to average $24 \mu \mathrm{g}$ zinc $/ \mathrm{kg} / \mathrm{d}$ and $6 \mu \mathrm{g}$ copper $/ \mathrm{kg} / \mathrm{d}$ (34). Thus, enterally fed infants appear to have greater amounts of endogenous fecal losses of zinc and copper. Furthermore, the endogenous fecal loss of zinc and copper in PTHM-fed infants appears substantially lower than that for infants fed PF, TF, and FPTHM; this difference was significant for copper between PTHM- and PF-fed infants and additional studies might demonstrate other significant differences. Although neither endogenous fecal zinc nor copper loss were significantly related to postnatal or postconceptional age (Table 5), postnatal age accounted for about $10 \%$ of the variability in endogenous fecal zinc loss (Table 6). This observation suggests that the zinc and copper contents provided in the formulas and human milk fortifier used in this study may need to be increased. Unfortunately, our data are also consistent with suggestions $(18,22)$ that fecal zinc and copper losses and endogenous fecal zinc and copper losses increase as dietary zinc and copper intake increase.

Univariate linear regression and multiple linear regression using the stepwise regression procedure were used to compare measurements of dietary zinc and copper absorption obtained with extrinsic stable isotopic tags and standard nutrient balance methods and to evaluate the effects of a number of variables on measures of zinc and copper availability from the 33 balance studies performed with PF. As shown in Figures 1 to 4, measures of zinc and copper absorption obtained with both methods were significantly correlated. In addition, average daily wt gain and the percentages of net fat and nitrogen absorption were significantly associated with measures of zinc and copper availability (Tables 5 and 6). Inasmuch as increments in body wt should be associated with zinc and copper accretion, the significant correlation with average daily wt gain seems appropriate. A significant correlation between net zinc balance and net fat and nitrogen absorption has been described (20). In addition, because most of 
the measures of zinc and copper availability were related to fat excretion (Table 6), and because pasteurization of human milk significantly decreases fat absorption in VLBW infants (36), the use of pooled pasteurized human milk might contribute to the prolonged period of negative net zinc and copper balance described by some investigators $(18,19,22)$.

Univariate regression analysis with data from the 33 balance studies performed with PF (Table 5) also demonstrated that measures of net zinc and copper absorption and retention were not significantly related to postnatal age or postconceptional age. This appears to differ from previous reports $(19,23)$. However, the percentages of ${ }^{70} \mathrm{Zn}$ and ${ }^{65} \mathrm{Cu}$ absorption were significantly correlated with postconceptional age, and the percent ${ }^{70} \mathrm{Zn}$ absorption approached a significant association with postnatal age. Furthermore, postconceptional age accounted for $7.5 \%$ of the variability in the percent ${ }^{65} \mathrm{Cu}$ absorption (Table 6). Unfortunately, the majority of our balance studies was performed with infants between 2 and $6 \mathrm{wk}$ old, and only a few of them had postconceptional ages of more than $36 \mathrm{wk}$. In addition, although no significant differences were observed in the zinc and copper balance data between the first and second balances in the nine infants studied twice, these studies were only separated by an average of $19 \mathrm{~d}$. Therefore, our studies might be distributed over too narrow a time period to show a relationship between net zinc and copper absorption and postnatal or postconceptional age. We have previously reported that ${ }^{70} \mathrm{Zn}$ absorption was not related to postnatal or postconceptional age; but those studies were also performed within a relatively narrow time period, essentially 3 to $6 \mathrm{wk}$ postnatally and 31 to $35 \mathrm{wk}$ postconception (4).

Although multiple linear regression analyses identified variables that together produced statistically significant effects (Table 6 ), they accounted for less than $60 \%$ of the total variability in the measures of zinc and copper availability. Of the variables tested, average daily wt gain entered the models most often, and accounted for about $20 \%$ of the variability in the measures of zinc absorption and retention and between 15.8 and $28.7 \%$ of the variability in the measures of copper absorption and retention. As stated above, because wt gain should be associated with accretion of zinc and copper, these correlations are appropriate. The percentages of net fat absorption accounted for about 6 to $23 \%$ of the variability in some of the models of zinc and copper availability; the effect of net fat absorption and net nitrogen absorption on copper absorption and retention were almost interchangeable. Dietary intakes of zinc and copper contributed to models of the percentage of net zinc absorption and retention, suggesting the possibility of a zinc-copper interaction. Such an interaction has been described (35).

In conclusion, this investigation has demonstrated that the extrinsic stable isotopic tags ${ }^{70} \mathrm{Zn}$ and ${ }^{65} \mathrm{Cu}$ can be used to study absorption of dietary zinc and copper in VLBW infants. The percentages of absorption of ${ }^{70} \mathrm{Zn}$ and of ${ }^{65} \mathrm{Cu}$ administered with formula or PTHM were significantly correlated with the percentages of net dietary zinc and copper absorption by VLBW infants (Figs. 1 and 3). True zinc and copper absorption were also significantly correlated with net zinc and net copper absorption, respectively (Figs. 2 and 4). The percentages of net zinc and copper absorption and retention from PTHM were found to be significantly greater than from formula, but similar to the net absorption and retention from F-PTHM (Tables 3 and 4). The ${ }^{70} \mathrm{Zn}$ and ${ }^{65} \mathrm{Cu}$ absorption data supported this observation, suggesting that PTHM might facilitate the absorption of supplemental zinc and copper included in human milk fortifiers. Net zinc and copper absorption and retention and true copper absorption were similar between diets; true zinc absorption from F-PTHM was significantly greater than from PTHM and TF. Estimates of endogenous fecal losses of zinc and copper were substantial with each diet, although the amount estimated for PTHM-fed infants was lower than that estimated for the other diets. Data from the $33 \mathrm{PF}$-fed infants demonstrated that the percentages of ${ }^{70} \mathrm{Zn}$ and ${ }^{65} \mathrm{Cu}$ absorption significantly correlated with postconceptional age; the correlation between ${ }^{70} \mathrm{Zn}$ absorption and postnatal age approached significance (Table 5). Finally multiple linear regression analysis using the stepwise regression procedure with data from the PF-fed infants demonstrated that we could account for, at most, $58 \%$ of the variability in measures of dietary zinc and copper availability; average daily wt gain and the percent net fat absorption entered the mineral availability models most often (Table 6).

Acknowledgments. The authors thank the nurses of the Newborn Special Care Unit for their assistance during the nutritional balance studies and Debra Camputaro for secretarial assistance in the preparation of the manuscript.

\section{REFERENCES}

1. American Academy of Pediatrics Committee on Nutrition: nutritional needs of low-birth weight infants 1977 Pediatr 60:519-530

2. American Academy of Pediatrics Committee on Nutrition: nutritional needs of low-birth-weight infants 1985 Pediatr 75:976-986

3. Cooke RJ, Perrin F, Moore J, Paule C, Ruckman K 1988 Methodology of nutrient balance studies in the preterm infant. J Pediatr Gastroenterol Nutr 7:434-440

4. Ehrenkranz RA, Ackerman BA, Nelli CM, Janghorbani M 1984 Determination with stable isotopes of the dietary bioavailability of zinc in premature infants. Am J Clin Nutr 40:72-81

5. Ehrenkranz RA, Ackerman BA, Nelli CM, Janghorbani M 1985 Absorption of calcium in premature infants as measured with a stable isotope ${ }^{46} \mathrm{Ca}$ extrinsic tag. Pediatr Res 19:178-184

6. Barltrop D, Mole RH, Sutton A 1977 Absorption and endogenous faecal excretion of calcium by low birthweight infants on feeds with varying contents of calcium and phosphate. Arch Dis Child 52:41-49

7. Hillman LS, Tack E, Covell DG, Vieira NE, Yergey AL 1988 Measurement of true calcium absorption in premature infants using intravenous ${ }^{46} \mathrm{Ca}$ and oral ${ }^{44} \mathrm{Ca}$. Pediatr Res 23:589-594

8. Liu Y, Neal P, Ernst J, Weaver C, Rickard K, Smith DL, Lemons IJ 1989 Absorption of calcium and magnesium from fortified human milk by low birth weight infants. Pediatr Res 25:496-502

9. Fomon SJ, Janghorbani M, Ting BTG, Ziegler EE, Rogers RR, Nelson SE, Ostedgaard LS, Edwards BB 1988 Erythrocyte incorporation of ingested 58iron by infants. Pediatr Res 24:20-24

10. Janghorbani M, Young VR 1980 Use of stable isotopes to determine bioavailability of minerals in human diets using the method of fecal monitoring. Am J Clin Nutr 33:2021-2030

11. Janghorbani M, Young VR 1980 Stable isotope methods for bioavailability assessment of dietary minerals in humans. Adv Nutr Res 3:127-155

12. Ehrenkranz RA, Gettner PA, Nelli CA 1989 Nutrient balance studies in premature infants fed premature formula or fortified-preterm human milk. J Pediatr Gastroenterol Nutr 8:58-67

13. Ting BTG, Janghorbani M 1987 Application of ICP-MS to accurate isotopic analysis for human metabolic studies. Spectrochim Acta 42B:21-27

14. Ting BTG, Kasper LJ, Young VR, Janghorbani M 1984 Copper absorption in healthy young men: Studies with stable isotope ${ }^{65} \mathrm{Cu}$ and neutron activation analysis. Nutr Res 4:757-769

15. Zar JH 1984 Simple linear regression. In:Biostatistical Analysis. Prentice-Hall, Inc., Englewood Cliffs, NJ, pp 272-276

16. Shaw JCL 1979 Trace elements in the fetus and young infant. I. Zinc. Am J Dis Child 133:1260-1268

17. Shaw JCL 1980 Trace elements in the fetus and young infant. II. Copper, manganese, selenium, and chromium. Am J Dis Child 134:74-81

18. Casey CE, Hambidge KM 1985 Trace minerals. In: Tsang RC (ed) Vitamin and Mineral Requirements in Preterm Infants. Marce Dekker, Inc., New York, pp 153-184

19. Dauncey MJ, Shaw JCL, Urman J 1977 The absorption and retention of magnesium, zinc, and copper by low birth weight infants fed pasteurized human breast milk. Pediatr Res 11:991-997

20. Voyer M, Davakis M, Antener I, Valleur D 1982 Zinc balances in preterm infants. Biol Neonate 42:87-92

21. Mendelson RA, Bryan MH, Anderson GH 1983 Trace mineral balances in preterm infants fed their own mother's milk. J Pediatr Gastroenterol Nutr 2:256-261

22. Tyrala EE 1986 Zinc and copper balances in preterm infants. Pediatrics $77: 513-517$

23. Higashi A, Ikeda T, Iribe K, Matsuda I 1988 Zinc balance in premature infants given the minimal dietary zinc requirement. J Pediatr 112:262-266

24. Casey CE, Walravens PA, Hambidge KM 1981 Availability of zinc: loading tests with human milk, cow's milk, and infant formulas. Pediatrics 68:394396

25. Sandstrom B, Cederblad A, Lonnerdal B 1983 Zinc absorption from human milk, cow's milk, and infant formulas. Am J Dis Child 137:726-729

26. Molokhia M, Sturniolo G, Shields R, Turnberg LA 1980 A simple method for measuring zinc absorption in man using a short-lived isotope $\left({ }^{69 \mathrm{~m}} \mathrm{Zn}\right)$. Am J Clin Nutr 33:881-886

27. Aamodt RL, Rumble WF, Johnston GS, Markley EJ, Henkin RI 1981 Ab- 
sorption of orally administered ${ }^{65} \mathrm{Zn}$ by normal human subjects. Am J Clin Nutr 34:2648-2652

28. Istfan NW, Janghorbani M, Young VR 1983 Absorption of stable ${ }^{70} \mathrm{Zn}$ in healthy young men in relation to zinc intake. Am J Clin Nutr 38:187-194

29. King JC, Raynolds WL, Margen S 1978 Absorption of stable isotopes of iron, copper and zinc during oral contraceptive use. Am J Clin Nutr 31:11981203

30. Weber PM, O'Reilley S, Pollycove M, Shipley L 1969 Gastrointestinal absorption of copper: Studies with ${ }^{64} \mathrm{Cu},{ }^{95} \mathrm{Zn}$, a whole-body counter and scintillation camera. J Nucl Med 10:591-596

31. Bush JA, Mahoney JP, Markowitz H, Gubler CJ, Cartwright GE, Wintrobe MM 1955 Studies on copper metabolism. XVI. Radioactive studies in normal subjects and in patients with hepatolinticular degeneration. J Clin Invest 34:1766-1778

32. Morriss FH Jr 1979 Trace Minerals. Semin Perinatol 3:369-379

33. Hambidge KM, Casey CE 1981 Trace element requirements in premature infants. In: Lebenthal $\mathrm{E}$ (ed) Textbook of Gastroenterology and Nutrition in Infancy. Raven Press, New York, pp 595-610

34. Zlotkin SH, Buchanan BE 1983 Meeting zinc and copper intake requirements in the parenterally fed preterm and full-term infant. J Pediatr 103:441-446

35. O'Dell BL 1985 Bioavailability of and interactions among trace elements. In: Chandra RK (ed) Trace Elements in Nutrition of Children. Nestle Nutrition, Vevey/Raven Press, New York, pp 41-62

36. Williamson S, Finucane E, Ellis H, Gamsu HR 1978 Effect of heat treatment of human milk on absorption of nitrogen, fat, sodium, calcium, and phosphorus by preterm infants. Arch Dis Child 53:555-563

\section{APPENDIX}

The calculations involved in the measurement of absorption and endogenous fecal loss of zinc and copper are described below $(4,10,11,13,14)$. Three stable isotopes of zinc were employed: ${ }^{67} \mathrm{Zn}$ (in vitro spike), ${ }^{68} \mathrm{Zn}$ (reference isotope), and ${ }^{70} \mathrm{Zn}$ (in vivo tracer). Inasmuch as copper is biisotopic, the isotope ratio measurement determined by ICP-MS was combined with elemental analysis (atomic absorption spectrophotometry).

For zinc:

$$
\begin{gathered}
\mathrm{R}_{67 / 68}=\mathrm{R}_{67 / 68}^{0}+\frac{{ }^{67} \mathrm{Zn}_{\text {spike }}}{{ }^{68} \mathrm{Zn}_{\mathrm{f}}} \\
\mathrm{R}_{70 / 68}=\mathrm{R}^{0}{ }_{70 / 68}+\frac{{ }^{70} \mathrm{Zn}_{\mathrm{f}}{ }^{6}}{{ }^{68} \mathrm{Zn}_{\mathrm{f}}}
\end{gathered}
$$

and

$$
\mathrm{Zn}_{\mathrm{f}}=5.208{ }^{68} \mathrm{Zn}_{\mathrm{f}}+{ }^{70} \mathrm{Zn}_{\mathrm{f}}{ }^{*}
$$

In these equations, $R_{67 / 68}$ and $R_{70 / 68}$ are the isotope ratios expressed on a wt basis for ${ }^{67} \mathrm{Zn} /{ }^{68} \mathrm{Zn}$ and ${ }^{70} \mathrm{Zn} /{ }^{68} \mathrm{Zn}$ determined in the in vivo labeled fecal pool; $\mathrm{R}_{67 / 68}^{0}$ and $\mathrm{R}^{0}{ }_{70 / 68}$ are the isotope ratios expressed on a wt basis for ${ }^{67} \mathrm{Zn} /{ }^{68} \mathrm{Zn}$ found in natural zinc, 0.2174 and 0.0344 respectively; ${ }^{67} \mathrm{Zn}_{\text {spike }}$ is the amount of ${ }^{67} \mathrm{Zn}$ added as a spike to the fecal sample; ${ }^{70} \mathrm{Zn}_{\mathrm{f}}{ }^{*}$ is the amount of ${ }^{70} \mathrm{Zn}$ in the stool collection originating from the in vivo tracer (excess ${ }^{70} \mathrm{Zn}$ ). $\mathrm{Zn}_{\mathrm{f}}$ is the total amount of zinc in the stool collection; and because ${ }^{68} \mathrm{Zn}$ is $19.2 \mathrm{wt}$ percent of natural zinc, $5.208{ }^{68} \mathrm{Zn}_{\mathrm{f}}$ equals the total amount of zinc in the stool collection originating from dietary intake and endogenous secretions.

In deriving equations (1) and (2), the assumption has been made that neither the ${ }^{67} \mathrm{Zn}$ spike nor the ${ }^{70} \mathrm{Zn}$ in vivo tracer introduce sufficient quantities of the other two stable isotopes of zinc to alter the values of $\mathrm{R}_{67 / 68}^{0}$ (equation 1 ) and $\mathrm{R}^{0}{ }_{70 / 68}$ (equation 2). This can generally be assured by the use of appropriately enriched isotopes. Therefore, to determine the value for ${ }^{68} \mathrm{Zn}$ and ${ }^{70} \mathrm{Zn}_{\mathrm{f}}{ }^{*}$, all that is required is accurate measurement of $\mathrm{R}_{67 / 68}$ and $\mathrm{R}_{70 / 68}$.

The fractional absorption of ${ }^{70} \mathrm{Zn}, \mathrm{F}\left({ }^{70} \mathrm{Zn}\right)$, can then be calculated as:

$$
\mathrm{F}\left({ }^{70} \mathrm{Zn}\right)=\frac{{ }^{70} \mathrm{Zn}_{0}{ }^{*}-{ }^{70} \mathrm{Zn}_{\mathrm{f}}{ }^{*}}{{ }^{70} \mathrm{Zn}_{0}{ }^{*}}
$$

endogenous fecal zinc loss, $\mathrm{Zn}_{\mathrm{e}}$, as:

$$
\mathrm{Zn}_{\mathrm{e}}=\mathrm{Zn}_{\mathrm{f}}-\left[1-\mathrm{F}\left({ }^{70} \mathrm{Zn}\right)\right] \mathrm{Zn}_{0}-{ }^{70} \mathrm{Zn}_{\mathrm{f}}{ }^{*}
$$

and net zinc absorption, $\mathrm{A}(\mathrm{Zn})_{\mathrm{n}}$, as:

$$
\mathrm{A}(\mathrm{Zn})_{\mathrm{n}}=\left[\mathrm{F}\left({ }^{70} \mathrm{Zn}\right)\right] \mathrm{Zn}_{0}-\mathrm{Zn}_{\mathrm{e}}
$$

In these equations, $\left.\mathrm{F}^{70} \mathrm{Zn}\right)$ is the fractional absorption of the in vivo tracer; ${ }^{70} \mathrm{Zn}_{0}$ * is the dose of ${ }^{70} \mathrm{Zn}$ given as the in vivo label; ${ }^{70} \mathrm{Zn}_{\mathrm{f}}{ }^{*}$ is the excess ${ }^{70} \mathrm{Zn}$ as defined above; and $\mathrm{Zn}_{\mathrm{e}}$ is the component of the total amount of zinc in the stool collection $\left(\mathrm{Zn}_{\mathrm{f}}\right)$ that is derived from endogenous secretions. Inasmuch as $\mathrm{Zn}_{0}$ is the total amount of dietary zinc intake. $\left[\mathrm{F}\left({ }^{70} \mathrm{Zn}\right)\right] \mathrm{Zn}_{0}$ is the true amount of dietary zinc absorbed; and $\mathrm{A}(\mathrm{Zn})_{\mathrm{n}}$ is the net amount of zinc absorption determined with the extrinsic isotopic tag method.

For copper:

$$
\begin{gathered}
\mathrm{R}_{65 / 63}=\mathrm{R}^{0}{ }_{65 / 63}+\frac{{ }^{65} \mathrm{Cu}_{\mathrm{f}}{ }^{*}}{{ }^{63} \mathrm{Cu}_{\mathrm{f}}} \\
\mathrm{Cu}_{\mathrm{f}}=1.4613{ }^{63} \mathrm{Cu}_{\mathrm{f}}+{ }^{65} \mathrm{Cu}_{\mathrm{f}}{ }^{*}
\end{gathered}
$$

where $\mathrm{R}_{65 / 63}$ is the mass isotope ratio expressed on a wt basis for ${ }^{65} \mathrm{Cu} /{ }^{63} \mathrm{Cu}$ determined in the fecal collection: $\mathrm{R}_{65 / 63}^{0}$ is the isotope ratio expressed on a wt basis for ${ }^{65} \mathrm{Cu} /{ }^{63} \mathrm{Cu}$ in natural copper, $0.4613 ;{ }^{65} \mathrm{Cu}_{\mathrm{f}}{ }^{*}$ is the amount of ${ }^{65} \mathrm{Cu}$ originating from the in vivo label that is recovered in the stool collection; ${ }^{63} \mathrm{Cu}_{\mathrm{f}}$ is the ${ }^{63} \mathrm{Cu}$ content of the stool collection, and $\mathrm{Cu}_{\mathrm{f}}$ is the total amount of copper in the stool collection. Inasmuch as the in vivo label used in this study, 99.69 atoms percent ${ }^{65} \mathrm{Cu}$, made an insignificant contribution to the ${ }^{63} \mathrm{Cu}$ content of the fecal content of ${ }^{63} \mathrm{Cu}$, and because ${ }^{63} \mathrm{Cu}$ is $68.43 \mathrm{wt}$ percent of natural copper, then $1.4613{ }^{63} \mathrm{Cu}_{\mathrm{f}}$ equals the total amount of copper in the stool collection originating from dietary intake and endogenous secretions.

Solving equations (7) and (8) yields:

$$
{ }^{65} \mathrm{Cu}_{\mathrm{f}} *=\frac{\mathrm{R}_{65 / 63}\left(\mathrm{Cu}_{\mathrm{f}}\right)-0.4613 \mathrm{Cu}_{\mathrm{f}}}{1+\mathrm{R}_{65 / 63}}
$$

Therefore, in order to determine ${ }^{65} \mathrm{Cu}_{\mathrm{f}}{ }^{*}$, accurate measurements of $\mathrm{R}_{65 / 63}$ and $\mathrm{Cu}_{\mathrm{f}}$ are required.

Similar to zinc, the fractional absorption of ${ }^{65} \mathrm{Cu}, \mathrm{F}\left({ }^{65} \mathrm{Cu}\right)$, is calculated as:

$$
\mathrm{F}\left({ }^{65} \mathrm{Cu}\right)=\frac{{ }^{65} \mathrm{Cu}_{0}^{*}-{ }^{65} \mathrm{Cu}_{\mathrm{f}}^{*}}{{ }^{65} \mathrm{Cu}_{0}^{*}}
$$

endogenous fecal copper loss, $\mathrm{Cu}_{\mathrm{e}}$, as:

$$
\mathrm{Cu}_{\mathrm{e}}=\mathrm{Cu}_{\mathrm{f}}-\left[1-\mathrm{F}\left({ }^{65} \mathrm{Cu}\right)\right] \mathrm{Cu}_{0}-{ }^{65} \mathrm{Cu}_{\mathrm{f}}{ }^{*}
$$

and net copper absorption, $\mathrm{A}(\mathrm{Cu})_{\mathrm{n}}$, as:

$$
\mathrm{A}(\mathrm{Cu})_{\mathrm{n}}=\left[\mathrm{F}\left({ }^{65} \mathrm{Cu}\right)\right] \mathrm{Cu}_{0}-\mathrm{Cu}_{\mathrm{e}}
$$

